\title{
Inflammation in Alzheimer's Disease and Molecular Genetics: Recent Update
}

\author{
Zhi-Gang Zhang ${ }^{1} \cdot$ Yan $\mathrm{Li}^{2} \cdot$ Cheung Toa $\mathrm{Ng}^{1} \cdot$ You-Qiang Song ${ }^{1,3}$
}

Received: 29 October 2014/Accepted: 3 March 2015/Published online: 1 August 2015

(C) L. Hirszfeld Institute of Immunology and Experimental Therapy, Wroclaw, Poland 2015

\begin{abstract}
Alzheimer's disease (AD) is a complex agerelated neurodegenerative disorder of the central nervous system. Since the first description of AD in 1907, many hypotheses have been established to explain its causes. The inflammation theory is one of them. Pathological and biochemical studies of brains from $\mathrm{AD}$ individuals have provided solid evidence of the activation of inflammatory pathways. Furthermore, people with long-term medication of anti-inflammatory drugs have shown a reduced risk to develop the disease. After three decades of genetic study in $\mathrm{AD}$, dozens of loci harboring genetic variants influencing inflammatory pathways in AD patients has been identified through genome-wide association studies (GWAS). The most well-known GWAS risk factor that is responsible for immune response and inflammation in $\mathrm{AD}$ development should be APOE $\varepsilon 4$ allele. However, a growing number of other GWAS risk AD candidate genes in inflammation have recently been discovered. In the present study, we try to review the inflammation in $\mathrm{AD}$ and immunity-associated GWAS risk genes like HLA-DRB5/DRB1, INPP5D, $M E F 2 C, C R 1, C L U$ and TREM2.
\end{abstract}

Z.-G. Zhang and Y. Li contributed equally to this work.

You-Qiang Song

songy@hku.hk

1 School of Biomedical Sciences, The University of Hong Kong, Pokfulam, Hong Kong, People's Republic of China

2 Energy Research Institute of Shandong Academy of Sciences, Jinan, Shandong, People's Republic of China

3 State Key Laboratory for Cognitive and Brain Sciences, The University of Hong Kong, Pokfulam, Hong Kong, People's Republic of China
Keywords Inflammation - Alzheimer's disease . Genetics · GWAS · TREM2

\section{Introduction}

Alzheimer's disease (AD), firstly described by Alois Alzheimer in 1907 (Avramopoulos 2009), is an irreversible neurodegenerative disease and the most common cause of dementia in elderly adults. In the United States, more than 5.4 million people are affected by AD now (Alzheimers Association 2012). Approximately 35.6 million people are currently diagnosed with $\mathrm{AD}$ in the world (Alzheimers Association 2013). It is estimated that, as the population lifespan increases, the number of $\mathrm{AD}$ affected patients will triple by 2050 (Hebert et al. 2003).

Alzheimer's disease is clinically characterized by progressive loss of the ability of learning and memory, and a decline in other cognitive functions, ultimately resulting in dementia and death. Histopathologically, there are two principal hallmarks in AD: (1) extracellular amyloid deposits that primarily consist of amyloid beta $(A \beta)$ peptides and (2) neurofibrillary tangles resulting from the intracellular accumulation of hyper-phosphorylated microtubule-associated protein tau (Huang and Mucke 2012). To date, the mechanisms leading to the formation of these lesions and their underlying association with $\mathrm{AD}$ are still not adequately understood. Nevertheless, several competing theories have been proposed trying to explain the cause of $\mathrm{AD}$, including $\mathrm{A} \beta$ hypothesis, tau hypothesis, cholinergic hypothesis and inflammation hypothesis. Due to unsuccessful experimental and clinical results, cholinergic theory has not been widely accepted. On the contrary, the $A \beta$ and tau theories are well-known hypotheses due to their capability to explain most $\mathrm{AD}$ pathogenesis. 
However, it is insufficient for $\mathrm{A} \beta$ plaques and hyperphosphorylated tau to explain all the features of $\mathrm{AD}$. In 2008, a study discovered that significant burden of $\mathrm{A} \beta$ deposition found in elderly persons did not necessarily cause clinically cognitive impairments (Aizenstein et al. 2008). Moreover, clinically reduced $A \beta$ in the brain through immune-therapeutics did not improve the AD patients' cognitive functions (Holmes et al. 2008). These studies suggest that some other factors might have involved in $\mathrm{AD}$ pathogenesis.

Genetic efforts through the employment of large-scale genome-wide association studies (GWAS) to search for AD susceptibility genes in the inflammatory process have never stopped. $A P O E$ is supposed to be the original gene found to have a genetic linkage with AD (Strittmatter et al. 1993). Several years after this discovery, $A P O E$ was reported to play an essential role in AD inflammation (Guo et al. 2004). Most recently, in 2012, APOE was found to trigger an inflammatory cascade that weakens the bloodbrain barrier (BBB) through an inflammatory molecule known as cyclophilin A (CypA) (Bell et al. 2012). The researchers observed that APOE significantly raises levels of CypA. The increased CypA, in turn, activates a proinflammatory pathway that ultimately leads to the breakdown of the BBB. This is a typical case in which an AD susceptible gene is involved in the inflammatory process associated with AD pathogenesis. Over 20 years has passed since the discovery of an association of $A P O E$ with $\mathrm{AD}$ in 1993, and numerous genetic association studies have been published since then. In this review, we will not put emphasis on the results of all GWAS risk genes in AD [which have been extensively reviewed previously (Bettens et al. 2013; Guerreiro et al. 2012; Medway and Morgan 2014; Tanzi 2012; Tosto and Reitz 2013)], but rather on the most recently implicated GWAS risk genes proved or expected to be involved in the inflammatory process of $\mathrm{AD}$ pathogenesis.

\section{Inflammation in AD}

Inflammation is a systematic and complicated immune response to clear an invading pathogen, a traumatic event, or generally, an injurious agent. The agent may be from the organism itself (such as a necrotic cell) or foreign, for example, viruses and bacteria. The inflammation can be acute or chronic. The inflammatory reaction that involves in most neurodegenerative diseases (Craft et al. 2006; Liu et al. 2013; Pizza et al. 2011; Sudduth et al. 2013; Varnum and Ikezu 2012), is often termed "neuroinflammation". Microglia, which is supposed to be the resident macrophages of the brain, and atrocities are the main cells that involve in this process. In the brains of both $\mathrm{AD}$ individuals and transgenic animal models, it was found that $\mathrm{A} \beta$ plaques are surrounded by activated glial cells (Bauer et al. 1991; Cagnin et al. 2001; Fillit et al. 1991; Liu et al. 2013; Varnum and Ikezu 2012). Activated microglia and astrocytes strongly secrete inflammatory components such as pro-inflammatory cytokines, chemokines, complement, macrophage inflammatory proteins, monocyte chemoattractant proteins, reactive oxygen species (ROS), nitric oxide (NO) prostaglandins, leukotrienes, thromboxanes and so on (Akiyama et al. 2000; Griffin et al. 1998; Mrak et al. 1995; Town et al. 2005; Tuppo and Arias 2005). The released inflammatory molecules, especially some cytokines such as interleukin (IL)-18, IL-1 $\beta$ and tumor necrosis factor (TNF)- $\alpha$, impair the balance of normal neurophysiologic condition that correlates with cognition and learning and memory (Fillit et al. 1991; Gemma and Bickford 2007; Jankowsky and Patterson 1999; Liu et al. 2013; Varnum and Ikezu 2012). These secreted inflammatory mediators, in turn, activate more microglia and astrocytes to produce inflammatory molecules. In addition, immune cells including, $\mathrm{T}$ cells, $\mathrm{B}$ cells and monocytes are found to migrate from the periphery through the $\mathrm{BBB}$ and present in the brains of AD individuals (Conductier et al. 2010; Ruan et al. 2010; Savarin-Vuaillat and Ransohoff 2007).

\section{Microglia and Astrocytes}

Microglia are derived from monocyte precursor cells during embryonic development. They are generally considered to be the main resident macrophage species in the brain. Microglia are recognized as the key players in the innate immune/inflammatory responses against the injury that occurs in AD (Mandrekar-Colucci and Landreth 2010). In the central nervous system (CNS), approximately $10 \%$ of the total cells are microglia (Benarroch 2013). Microglia are inactive under physiological condition. However, they can be stimulated by many factors including $A \beta$. Activated microglia changes the morphology; for instance, the branching and soma growth decreases, an amoeboid form appears as well as various specific markers on the cellular surface (Town et al. 2005). Activated microglia are phagocytic and able to migrate to clear the damaged cells or debris. They can also release inflammatory molecules such as ROS, cytokines, chemokines and some growth factors (Fig. 1).

Over two decades have passed, it is still impossible to make a conclusion about whether microglia should be considered as a friend or an enemy to CNS (Wyss-Coray and Rogers 2012). It was reported that, when microglia were moderately stimulated by low levels of $A \beta$, they had a strong capability to clear $A \beta$ through phagocytosis. However, if microglia were strongly activated by high concentration of $A \beta$, they tended to enhance the generation 
Fig. 1 Scheme of inflammation in Alzheimer's disease. A $\beta$ peptides released by neurons, oligomerize and form $A \beta$ fibrils that activate microglia and actrocytes. Activated glia cells produce inflammatory cytokines and chemokines, iNOS, some growth factors, ROS and NO. In response to the fibrillar $\mathrm{A} \beta$ stress, the complement system is also activated, resulting in enhanced phagocytosis or even cytolysis induced cell death

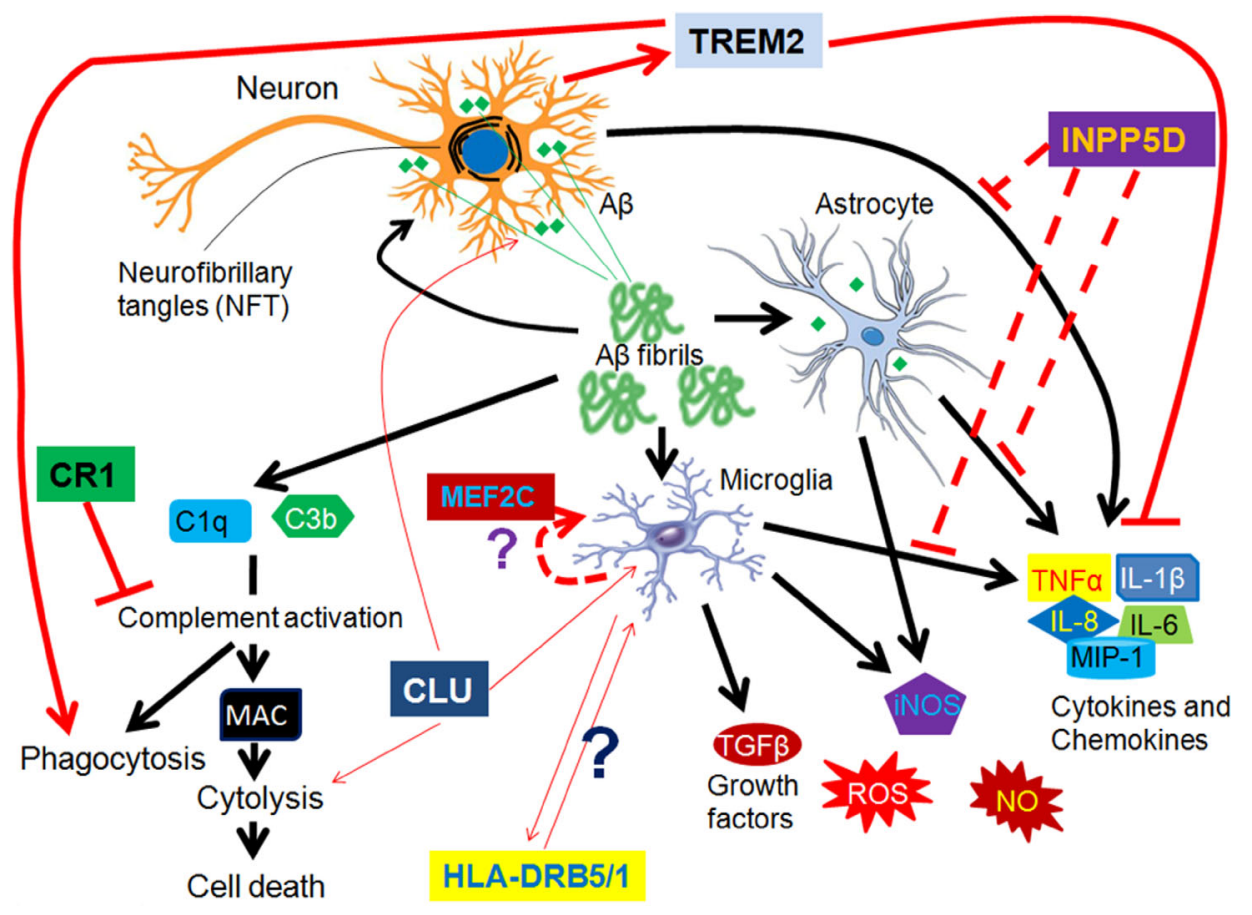

of pro-inflammatory molecules, such as IL- $1 \beta$ and TNF- $\alpha$, resulting in neuronal damage and compromised ability of A $\beta$ clearance (Liu and Chan 2014). Therefore, it seems that microglia in $\mathrm{AD}$ is like a double-edged sword. It can be either beneficial or detrimental, but not both at the same time.

Unlike microglia, astrocytes are generally treated to be the most abundant cells that support neurons in the brain (Sofroniew and Vinters 2010). They interact with neurons and are known to be involved in regulating the secretion and recycling of neurotransmitters, synaptic remodeling, energy metabolism, ion homeostasis as well as oxidative stress (Halassa and Haydon 2010; Henneberger et al. 2010). In AD, though the mechanisms are still elusive, it has been demonstrated that astrocytes can be activated in the presence of $\mathrm{A} \beta$. Compared with quiescent astrocytes, reactive astrocytes can encircle senile plaques and form a cell barrier between the plaques and healthy neurons (Sofroniew and Vinters 2010). However, although astrocytes activation has a protective role for the brain, the role of astrocytes may not be beneficial under certain conditions. Several reports suggested that reactive astrocytes could be a producer for low amount of $A \beta$ in addition to neurons, which are the major source of $A \beta$ (Liu and Chan 2014). In vitro studies showed that, in response to $A \beta$, cultured astrocytes significantly overexpress a number of inflammatory related factors such as IL- $1 \beta$, TNF- $\alpha$, inducible NO synthase (iNOS), and NO (Fig. 1; White et al. 2005).

\section{Neuron}

As the core components of the brain, neurons were traditionally not treated as a part of neuroinflammation. However, some interesting evidence suggests that neurons also participate in the inflammatory response in the CNS. For examples, neurons can produce COX-2-derived prostanoids (Davis and Laroche 2003; Natarajan and Bright 2002; Pavlov and Tracey 2005), several cytokines such as IL-1 $\beta$ and IL-18 (de Rivero Vaccari et al. 2008; Fann et al. 2013; Zou and Crews 2012), complement and macrophage colony-stimulating factor (Du Yan et al. 1997). Moreover, in the brain of AD individuals, an inflammation-induced enzyme named iNOS has been reported to be expressed by degenerating neurons (Heneka et al. 2001; Lee et al. 1999; Vodovotz et al. 1996).

On the other hand, it has been noted that neurons are able to generate various molecules that are demonstrated to suppress inflammation, such as TREM2, CD22, CD200, CD59 and fractalkine (Hsieh et al. 2009; Mott et al. 2004; Ransohoff 2007; Singhrao et al. 1999; Walker et al. 2009). Interestingly, several of these molecules have been found to be deficient in AD. For instance, the expression of CD200 and CD59 was reported to be down-regulated in neurons of AD brain (Walker et al. 2009; Yang et al. 2000). Generally, studies in the expression of inflammatory molecules in neurons of $\mathrm{AD}$ individuals are still not fully explored, and more investigations into this area are needed. 


\section{The Complement System}

The complement system is an essential part in activating and executing of immune responses (Wyss-Coray and Rogers 2012). This system consists of around 30 cellmembrane-associated and cytosolic proteins that are activated in cascade (Forneris et al. 2012). The factors of this system mainly have four biological functions, namely, recognition, opsonization, inflammatory stimulation through anaphylatoxins and direct killing through the membrane attack complex (MAC) (McGeer and McGeer 2002). Generally, certain molecular patterns on pathogens are recognized either by $\mathrm{C} 1 \mathrm{q}$ molecule, mannose-binding proteins containing collagen-like receptor binding domains, or through the interaction with the C3 multifunctional protein (Sahu and Lambris 2001; Tenner 1999). Activated C3 recruits immune cells, amplifies antigenspecific immune responses, promotes phagocytosis, forms MAC by binding $\mathrm{C} 5, \mathrm{C} 6, \mathrm{C} 7, \mathrm{C} 8$ and $\mathrm{C} 9$ to facilitate complement-mediated cytolysis, and executes the cell death (Ricklin et al. 2010).

Complement proteins and receptors are mostly generated in the liver and have high concentrations in serum. However, many of them can be synthesized locally in the brain as well (Barnum 1995; Gasque et al. 1995; Morgan and Gasque 1996; Nataf et al. 1999). The abnormality of the complement system has been reported in brain injury and neurodegenerative disease (D'Ambrosio et al. 2001; Gasque 2004), including AD. In the brain of AD patient, it has been observed that the expression of C1q, C3b, C4d and $\mathrm{C} 5 \mathrm{~b}-9$ is elevated, and the MAC colocalizes with senile plaques and tangle-positive neurons (Blalock et al. 2004; Fonseca et al. 2004; Katsel et al. 2009; Shen et al. 2001). In addition, in the microvasculature, microglia are reported to surround the fibrillar $A \beta$ deposits (Fan et al. 2007). In vitro studies demonstrated that $A \beta$ aggregates activated the complement system by binding $\mathrm{C} 1 \mathrm{q}$ or $\mathrm{C} 3 \mathrm{~b}$ (Jiang et al. 1994; Rogers et al. 1992). Neurofibrillary tangles or aggregated tau were also observed to activate the classical pathway (Shen et al. 2001). In conclusion, both of $\mathrm{A} \beta$ and tau in $\mathrm{AD}$ can activate the complement system. Activated complement system is essential for the elimination of cell debris and the clearance of protein $A \beta$ and/or tau aggregates, though it also promotes unwanted inflammation (Shen and Meri 2003).

\section{Inflammatory Cytokines and Chemokines}

Cytokines, mainly produced by immune system cells, are nonstructural soluble proteins with low molecular weights $(8-40 \mathrm{kDa})$. They can be synthesized by a variety of immune cells including macrophages, $\mathrm{T}$ lymphocytes, natural killer (NK) cells and some non-immune cells as well, such as fibroblasts and Schwann cells. In the CNS, however, cytokines are secreted by microglia and astrocytes and have been linked to CNS development. Moreover, enhanced expression of proinflammatory cytokines, such as IL-6, IL-10, IL-1 $\beta$, TNF- $\alpha$, are observed in the brain and cerebrospinal fluid (CSF) of Alzheimer's patients (Blum-Degen et al. 1995; Jiang et al. 2011; Mrak and Griffin 2005; Tarkowski et al. 2002). In the animal models of $\mathrm{AD}$, the expression level of TNF- $\alpha$, IL-1 $\alpha$ and IL-1 $\beta$ was also reported to be elevated (Apelt and Schliebs 2001; Benzing et al. 1999; Matsuoka et al. 2001; Sly et al. 2001). The production of these pro-inflammatory cytokines leads to microglial activation, astrogliosis, and induce the release of other pro-inflammatory molecules, amplifying the cytokine effects. The exact consequences of altered cytokines on brain function and neurodegeneration related to $\mathrm{AD}$ are still elusive, but growing evidence in $\mathrm{AD}$ model mice suggests that these inflammatory molecules may have potent effects on neurodegeneration, amyloidosis and learning and memory (Wyss-Coray 2006; Wyss-Coray and Mucke 2002). For example, in AD transgenic animals, cytokines are found to increase the susceptibility to A $\beta$ deposition (Games et al. 1995; Guo et al. 2002) and upregulate beta-secretase 1 both at mRNA and protein level, as well as its enzymatic activity (Sastre et al. 2003).

Chemokines are the largest family of cytokines in human immunology. Their major function is to recruit immune cells, such as macrophages, lymphocytes, monocytes, neutrophils, basophils and dendritic cells toward sites where an inflammatory response is required (MerazRios et al. 2013). Chemokines exert their biological effects through association with specific G-protein-coupled receptors called chemokine receptors which can be divided into four families, CXCR, CCR, CX3CR1 and XCR1 (Azizi et al. 2014). Growing evidence has shown that chemokines and their receptors are increased in the CNS, which may play important roles in neuroinflammation of neurodegenerative diseases, including AD, Parkinson's disease, multiple sclerosis, human immunodeficiency virus-associated dementia, and stroke (Duan et al. 2008; Ruan et al. 2010). In the brain of AD patients, monocyte chemotactic proteins, like MCP-1 or CCL2, and chemokine receptors including CCR3 and CCR5 are found to be present in activated microglia surrounding amyloid deposits. Even in the prodromal stage of $\mathrm{AD}$, the expression of several chemokines such as inducible protein 10, CCL2, and CXCL8 are elevated both in brain tissue and CSF. In vitro studies demonstrated that $A \beta$ peptide stimulated human monocytes to release chemokines such as IL-8 (CXCL8), macrophage inflammatory protein (MIP)-1 $\alpha$, MIP-1 $\beta$ and MCP-1. Moreover, it is observed that the 
expression of IL-8, MIP- $1 \alpha$ and MCP-1 after exposure to $\mathrm{A} \beta$ is upregulated in cultured microglia from rapid autopsies of AD patients and control individuals.

\section{Molecular Genetics}

It has been widely accepted that genetic factors play a key role in AD. It is estimated that approximately as much as $80 \%$ of the phenotypic variability in $\mathrm{AD}$ is genetically caused (Cruchaga et al. 2012). The search for genes involved in $\mathrm{AD}$ has been ongoing for over two decades since 1987 (Tanzi 2012). It did not bring much reward until the application of GWAS which has revolutionized genetics research. Currently, GWAS has been the most common strategy to evaluate genetic variants in the genome using single nucleotide polymorphism (SNP) arrays to study the association with AD (Sherva and Farrer 2011). It can assess over one million SNPs in a single individual, genotype large number of populations (over 1000 subjects) and identify candidate genes in an unbiased manner (Mullane and Williams 2013). In 2009, the first replicable GWAS confirmed $A P O E$ as the first genetic risk factor for late-onset $\mathrm{AD}$ (LOAD). Since then, as a result of European and international genome-wide association collaborations, at least nine novel risk loci have been reported, including CR1, BIN1, CD2AP, EPHA1, CLU, MS4A6A, PICALM, $A B C A 7$ and $C D 33$ (Harold et al. 2009; Hollingworth et al. 2011; Lambert et al. 2009; Naj et al. 2011; Seshadri et al. 2010). Recently, a meta-analysis by the International Genomics of Alzheimer's Project found 11 new AD risk genes, including CASS4, CELF1, FERMT2, HLA-DRB5/ DRB1, INPP5D, MEF2C, NME8, PTK2B, SLC24A4/RIN3, SORLI and ZCWPW1. Additionally, it confirmed 8 (CR1, BIN1, CD2AP, EPHA1, CLU, MS4A6A, PICALM and $A B C A 7)$ of the nine previously reported $\mathrm{AD}$ associated genes, in which $C D 33$ was ruled out due to the failure to replicate (Lambert et al. 2013). At the same time, two independent groups revealed TREM2 as a rare but significant risk for $\mathrm{AD}$ through exome sequencing (Guerreiro et al. 2013; Jonsson et al. 2013). Not surprisingly, several of these $\mathrm{AD}$ risk molecules are involved in immune and inflammatory process (Bagyinszky et al. 2014). In this review, due to limitations of space, we mainly focus on these six genes: $C R 1, C L U, H L A-D R B 5 / D R B 1$, INPP5D, $M E F 2 C$, and TREM2.

\section{Complement Receptor 1}

The complement receptor 1 (CR1, also referred as CD35) is the receptor for the activated form of $\mathrm{C} 3 \mathrm{~b}$ and $\mathrm{C} 4 \mathrm{~b}$ complement components (Iida et al. 1982). The CRI gene is located on chromosome 1 at the locus $1 \mathrm{q} 32$ in a genetic cluster of complement activation genes (de Cordoba and Rubinstein 1986). CR1 is a multifunctional protein, which is widely expressed on the extracellular membrane of, $\mathrm{B}$ lymphocytes, monocytes, macrophages, erythrocytes, eosinophils, some CD4-positive T cells, dendritic cells, Langerhan cells in the skin glomerular podocytes and microglia as well (Crehan et al. 2013; Klickstein et al. 1988, 1997; Korotzer et al. 1995; Liu and Niu 2009). CR1 has two isoforms: CR1-F and CR1-S, where the F means the "fast" isoform with a smaller molecular weight while the S refers to "slow" isoform (Aiyaz et al. 2012). In addition, the expression of CR1-S isoform is lower than CR1-F in the brain of AD patients, compared with controls (Hazrati et al. 2012). CR1 acts as an inhibitor of complement activation through two pathways that lead to the dampening of the immune response and limiting surrounding tissue damage. The first one is that $\mathrm{CR} 1$, by reversibly binds binding to $\mathrm{C} 3 \mathrm{~b}$ and $\mathrm{C} 4 \mathrm{~b}$, inactivates the $\mathrm{C} 3$ and $\mathrm{C} 5$ convertases, the multi-protein complexes including $\mathrm{C} 3 \mathrm{~b}$ and $\mathrm{C} 4 \mathrm{~b}$. The second mechanism is that $\mathrm{CR} 1$ can promote the dissociation of the catalytic subunits $\mathrm{C} 2 \mathrm{a}$ or $\mathrm{Bb}$ leading to acceleration of the decay of the $\mathrm{C} 3$ convertase (Liu and Niu 2009). In the brain, the exact mechanisms of how CR1-mediated complement regulates AD pathogenesis are elusive. However, it is speculated that CR1 is likely to be beneficial to $\mathrm{AD}$ through $\mathrm{C} 3 \mathrm{~b}$-mediated clearance of $\mathrm{A} \beta$ deposits from the brain and/or protecting healthy neurons from inflammation-mediated impairment (Fig. 1). Several interesting hypotheses have been proposed, for example, the deficiency in C3b-mediated clearance of neurotoxic $A \beta$ deposits from the brain and the potential beneficial effect through minimizing inflammation-mediated impairment of healthy neurons (Aiyaz et al. 2012; Thambisetty et al. 2013).

\section{Clusterin}

Clusterin (CLU), also known as apolipoprotein $\mathbf{J}$, is a multifunctional glycoprotein, which was originally described because of its capability to induce cell aggregating in vitro (Blaschuk et al. 1983). CLU mRNA is widely expressed (de Silva et al. 1990) and the mature CLU product is secreted out of the cell to serve as an extracellular chaperone (Carver et al. 2003; Wyatt et al. 2009). Secreted CLU is a heavily glycosylated, $75-80-\mathrm{kDa}$ heterodimeric protein that is linked by five disulfide bonds (Choi-Miura et al. 1992). CLU is reported to participate in numerous biological processes including roles in sperm maturation (Blaschuk et al. 1983), complement-mediated cell lysis (Hochgrebe et al. 1999), lipid transport (Jenne et al. 1991) and apoptosis (Kim et al. 2010; Scaltriti et al. 2004). The association between $C L U$ and $\mathrm{AD}$ has been well demonstrated. Initially, the expression level of CLU was found to 
be significantly elevated in the $\mathrm{AD}$ brain regions than compared with control subjects (May et al. 1990). Moreover, CLU was reported to be present in amyloid plaques (Giannakopoulos et al. 1998). In addition, recent studies have revealed that the concentration of CLU in the CSF and plasma of AD patients is significantly elevated (Sihlbom et al. 2008; Thambisetty et al. 2010). Interestingly, as a chaperone protein, CLU has been proven to interact with $\mathrm{A} \beta$ peptides and this interaction plays an important role in $\mathrm{A} \beta$ aggregation, toxicity and clearance (Baig et al. 2012; DeMattos et al. 2002; Narayan et al. 2012; Yerbury et al. 2007). Also, several studies have suggested that $C L U$ is a potential modulator of inflammation in $\mathrm{AD}$ pathogenesis. Besides its role in complement-mediated cell lysis (which has been mentioned before), $C L U$ has been shown to involve in complement activation (Urbich et al. 2000). In 2005, one study showed that CLU could activate microglia both in vivo and in primary rat microglia in vitro (Fig. 1; $\mathrm{Xie}$ et al. 2005). Most recently, CLU was reported to participate in astrocyte and microglia mediated $A \beta$ clearance in vitro (Mulder et al. 2014). Moreover, CLU is suggested to indirectly regulate several inflammatory cytokines such as TNF- $\alpha$ and IL-6 (Yu and Tan 2012). In summary, though more evidence is needed, it seems that $C L U$ might be involved in $\mathrm{AD}$ pathogenesis though facilitating $A \beta$ aggregation, modulating astrocyte and microglia mediated $A \beta$ clearance and complement activation, and stimulating microglia activation (Fig. 1).

\section{HLA-DRB5/DRB1}

The human leukocyte antigen ( $H L A)$ region is located on chromosome 6p21.3 and encodes proteins for the major histocompatibility complex (MHC). In human, HLA is the name of MHC. HLA and MHC are often used interchangeably in the literature (Torres et al. 2012). The proteins encoded by HLA play an important role in immune response, including antigen processing and presentation, and selfrecognition by immune cells. Genes in this region are involved in a variety of pathways such as inflammation, the complement cascade, histocompatibility, and ligands for immune cell receptors (Downs-Kelly et al. 2007). The MHC complex can be divided into three subgroups: MHC classes I, II, and III, in which the class II MHC locates at the centromeric end and encodes genes including HLA-DRA, $D R B 1$, $-D R B 3,-D R B 4,-D R B 5,-D Q A 1,-D Q B 1,-D P A 1$ and $D P B 1$. The class II HLA-DR antigens are expressed by antigen-presenting cells, including microglia in the brain and they can interact with $\mathrm{T}$ cell receptors. It has been reported that HLA-DR positive activated microglia are found in the substantia nigra of Parkinson's disease individuals (McGeer et al. 1988; Orr et al. 2005) and animals with 1-methyl-4phenyl-1,2,3,6-tetrahydropyridine-induced parkinsonism
(Hirsch and Hunot 2009). The experimental evidence of how HLA-DR associates with AD is extremely limited, but it is reasonable to speculate that, as another important neurodegenerative disease, the situation of HLA-DR in AD (Fig. 1) is probably similar to that in Parkinson's disease.

\section{INPP5D}

As a member of the inositol polyphosphate-5-phosphatase (INPP5) family, INPP5D is better known as $\mathrm{SH} 2$ domain containing inositol-5'-phosphatase, SHIP (also SHIP1 or SHIP1 $\alpha$ ). The human SHIP protein, encoded by the INPP5D gene located on chromosome $2 \mathrm{q} 37.1$, is an enzyme that hydrolyses the $5^{\prime}$-phosphate of phosphatidylinositol (PI)-3,4,5-triphosphate $(\mathrm{PI}(3,4,5) \mathrm{P} 3)$ to generate PI-3,4-bisphosphate $(\mathrm{PI}(3,4) \mathrm{P} 2)$ (Arijs et al. 2012). SHIP is expressed predominantly by cells in the hematopoietic compartment (Kerr 2011). SHIP it is also found to be present in osteoblasts, mature granulocytes, monocyte/macrophages, mast cells, platelets and NK cells (Cox et al. 2001; Geier et al. 1997; Giuriato et al. 1997; Hazen et al. 2009; Maresco et al. 1999; Trotta et al. 2005). As for the biological functions of SHIP, it was discovered to be the key negative regulator of $\mathrm{IgE}+\mathrm{Ag}$-generated $\mathrm{PI}(3,4,5) \mathrm{P} 3$ levels in murine bone marrow derived mast cells (Huber et al. 1999). Also, SHIP negatively regulates IgE- or IgE + Ag-induced inflammatory cytokine release from mast cells, as well as B cell proliferation, chemotaxis and activation (Kalesnikoff et al. 2002; Kim et al. 1999; Sly et al. 2003, 2007). The function of SHIP in immune response and inflammation in the brain is still poorly understood. However, according to current knowledge about SHIP, it is possible that SHIP can suppress the release of various inflammatory cytokines from microglia, astrocytes or even neurons (Fig. 1).

\section{MEF2C}

The myocyte enhancer factor-2 (MEF2) proteins are members of the MADS (MCM1, agamous, deficiency, serum response factor) family of transcription factors (Naya and Olson 1999; Yu et al. 1992). In mammals, MEF2 proteins are encoded by four genes MEF2A, B, C, and $\mathrm{D}$. The four $M E F 2$ isoforms are expressed in overlapped, however, with different patterns, both in the tissues of embryos and adults (Potthoff and Olson 2007). MEF2C is more widely expressed and regulates diverse transcriptional events such as the development and differentiation of many tissues (Potthoff and Olson 2007). In addition, $M E F 2 C$ is found to be highly expressed in B cells of the spleen and lymph node (Swanson et al. 1998), and plays a critical role in B cell proliferation upon antigen stimulation (Khiem et al. 2008; Wilker et al. 2008). Recently, MEF2 is 
reported to be a central transcriptional component of the innate immune response in the adult fly (Clark et al. 2013). In the adult brain of human and rodent, $M E F 2 C$ is highly expressed in the regions closely associated with learning and memory, for instance, frontal cortex, entorhinal cortex, dentate gyrus, and amygdala (Leifer et al. 1994; Lyons et al. 1995). Recently, MEF2 is reported to be a central transcriptional component of the innate immune response in the adult fly (Clark et al. 2013). Therefore, it is a plausible possibility that MEF2 is also involved in the inflammatory process in the brains of individuals with $\mathrm{AD}$ through maybe regulating microglia proliferation (Fig. 1).

\section{TREM2}

Triggering receptor expressed on myeloid cells 2 (TREM2) is a member of the innate immune receptor TREM family, which is predicted to result in a $\mathrm{R} 47 \mathrm{H}$ substitution that causes an $\sim 3$-fold increase in the susceptibility to LOAD. TREM2 gene is located on chromosome 6p21.1 and encodes a $26-\mathrm{kDa}$ transmembrane glycoprotein that consists of an extracellular immunoglobulin-like domain, a transmembrane domain, and a short cytoplasmic tail (Colonna 2003). It is an innate immune receptor expressed on the extracellular membrane of activated macrophages, osteoclast, immature dendritic cells, and microglia in the brain (Takahashi et al. 2005). Its signaling capacity is carried out through forming a complex with the TYRO protein tyrosine kinase binding protein (TYROBP, also known as DAP12) (Paloneva et al. 2002). The TREM2/ TYROBP complex is reported to regulate key signaling pathways involved in differentiation of dendritic cells and osteoclasts, phagocytic activity in microglia and immune responses (Bouchon et al. 2001; Hsieh et al. 2009; Otero et al. 2012). In the CNS, it is revealed that TREM2 negatively regulates inflammatory responses by repression of cytokine production and secretion in response to both TLR2 and TLR4 ligands zymosan and LPS (Hamerman et al. 2006; Sessa et al. 2004; Turnbull et al. 2006). Therefore, TREM2 is speculated to be beneficial in AD pathogenesis (Fig. 1); its anti-inflammatory properties could reduce inflammation-induced innocent bystander neuronal damage (Boutajangout and Wisniewski 2013). In addition, TREM2 is also known to participate in the regulation of phagocytosis that responsible for removing damaged or apoptotic neurons (Fig. 1), which promote tissue repair in response to AD-related pathology (Jiang et al. 2013). People with a loss-of-function mutation of TREM2 have high risk to develop a chronic neurodegenerative disease (Nasu-Hakola disease) which is most probably due to the deficiency in eliminating tissue debris (Neumann and Takahashi 2007). Interestingly, it has been demonstrated that TREM2 is upregulated in $\mathrm{AD}$ mice
(Fig. 1; Frank et al. 2008), possibly in a failed compensatory attempt by the mice to keep the inflammatory response in check (Hickman and El Khoury 2014).

\section{Are These AD Risk Inflammation Associated Factors Potential Therapeutic Targets for AD?}

On the basis of amyloid and tau hypothesis, a variety of therapeutic approaches and compounds have been developed for AD. Almost all of these strategies have focused on reducing of $A \beta$ generation, aggregation, facilitating $A \beta$ clearance, or inhibiting the level of phosphorylated tau or total tau or their fibrillization. Despite the unsuccessful results of extensive basic and clinical trials (Giacobini and Gold 2013; Yoshiyama et al. 2013), we have learned much valuable experience and lesson from the failure. Although it has limitations for the $A \beta$ and tau cascade hypothesis, it is still a critical and useful theory to find novel potential therapeutic targets for AD. For example, just as what has been mentioned before, $C R 1$ and $C L U$ have been suggested to participate in $A \beta$ aggregation and clearance. For $H L A$ DRB5/DRB1, INPP5D, MEF2C, and TREM2, due to the limited basic research on their biological function in $A \beta$ and/or tau associated metabolism, it is too early to speculate whether they are part of this process. However, we cannot rule out the possibility that these four candidates may be potential targets for $\mathrm{AD}$ treatment, either. Up to now, one fact that should not be bypassed is, the only approved pharmacological agents for AD treatment are $N$ methyl-D-aspartate receptor antagonist memantine and the cholinesterase inhibitors (donepezil, rivastigmine, galantamine) (Giacobini and Gold 2013). And none of these compounds act through mechanisms that can be explained by $A \beta$ or tau cascade hypothesis. This interesting fact suggests that reduced level of $A \beta$ or hyper-phosphorylated tau, though they are still very useful, should not be treated as the only criterion in searching new therapeutic targets for $\mathrm{AD}$. These $\mathrm{AD}$ risk genes from GWAS should always be on the list of potential candidates for AD treatment, though the current evidence is too far from enough.

\section{Conclusion}

To date, the field of inflammation in $\mathrm{AD}$ has come a long way from its first discovery. Although a lot of evidence is tempting to conclude that inflammatory processes are the driving force of $\mathrm{AD}$ pathogenesis and that inhibiting inflammation would be beneficial, caution must be taken in deciding inflammation as the therapeutic target to prevent or treat the disease. Convincing data have demonstrated that many inflammatory molecules are like a double-edged 
sword, and it may cause more problems than it can solve by simply suppressing them. Despite the complexity of the mechanism involved in AD pathology, inflammatory pathway is worth considering as a potential candidate for therapeutic interventions.

Genetic research in AD has broadened our understanding of the causes of AD. GWAS has become the most common method for identifying novel AD genes. Tens of $\mathrm{AD}$ risk genes have been identified in recent years. Several newly confirmed genes provide more clues about the involvement of inflammation in AD. Although the mechanism of how inflammation in AD is influenced by these genes (CR1, CLU, HLA-DRB5/DRB1, INPP5D, MEF2C, and TREM2) is still poorly known, these genes add new knowledge to our understanding of AD and may act as promising therapeutic targets to improve the prevention and treatment of $\mathrm{AD}$.

Acknowledgments This work was supported by a grant from NSFC Grant (No. 81271226 to Y. Q. Song).

\section{References}

Aiyaz M, Lupton MK, Proitsi P et al (2012) Complement activation as a biomarker for Alzheimer's disease. Immunobiology 217:204-215

Aizenstein HJ, Nebes RD, Saxton JA et al (2008) Frequent amyloid deposition without significant cognitive impairment among the elderly. Arch Neurol 65:1509-1517

Akiyama H, Arai T, Kondo $\mathrm{H}$ et al (2000) Cell mediators of inflammation in the Alzheimer disease brain. Alzheimer Dis Assoc Disord 14(Suppl 1):S47-S53

Alzheimers Association (2012) 2012 Alzheimer's disease facts and figures. Alzheimers Dement 8:131-168

Alzheimers Association (2013) 2013 Alzheimer's disease facts and figures. Alzheimers Dement 9:208-245

Apelt J, Schliebs R (2001) Beta-amyloid-induced glial expression of both pro- and anti-inflammatory cytokines in cerebral cortex of aged transgenic Tg2576 mice with Alzheimer plaque pathology. Brain Res 894:21-30

Arijs I, De Hertogh G, Lemmens B et al (2012) Intestinal expression of SHIP in inflammatory bowel diseases. Gut 61:956-957

Avramopoulos D (2009) Genetics of Alzheimer's disease: recent advances. Genome Med 1:34

Azizi G, Khannazer N, Mirshafiey A (2014) The potential role of chemokines in Alzheimer's disease pathogenesis. Am J Alzheimers Dis Other Dement. doi:10.1177/1533317513518651

Bagyinszky E, Youn YC, An SS et al (2014) The genetics of Alzheimer's disease. Clin Interv Aging 9:535-551

Baig S, Palmer LE, Owen MJ et al (2012) Clusterin mRNA and protein in Alzheimer's disease. J Alzheimers Dis 28:337-344

Barnum SR (1995) Complement biosynthesis in the central nervous system. Crit Rev Oral Biol Med 6:132-146

Bauer J, Strauss S, Schreiter-Gasser U et al (1991) Interleukin-6 and alpha-2-macroglobulin indicate an acute-phase state in Alzheimer's disease cortices. FEBS Lett 285:111-114

Bell RD, Winkler EA, Singh I et al (2012) Apolipoprotein E controls cerebrovascular integrity via cyclophilin A. Nature 485:512-516

Benarroch EE (2013) Microglia: multiple roles in surveillance, circuit shaping, and response to injury. Neurology 81:1079-1088
Benzing WC, Wujek JR, Ward EK et al (1999) Evidence for glialmediated inflammation in aged $\mathrm{APP}(\mathrm{SW})$ transgenic mice. Neurobiol Aging 20:581-589

Bettens K, Sleegers K, Van Broeckhoven C (2013) Genetic insights in Alzheimer's disease. Lancet Neurol 12:92-104

Blalock EM, Geddes JW, Chen KC et al (2004) Incipient Alzheimer's disease: microarray correlation analyses reveal major transcriptional and tumor suppressor responses. Proc Natl Acad Sci USA 101:2173-2178

Blaschuk O, Burdzy K, Fritz IB (1983) Purification and characterization of a cell-aggregating factor (clusterin), the major glycoprotein in ram rete testis fluid. J Biol Chem 258:7714-7720

Blum-Degen D, Muller T, Kuhn W et al (1995) Interleukin-1 beta and interleukin-6 are elevated in the cerebrospinal fluid of Alzheimer's and de novo Parkinson's disease patients. Neurosci Lett 202:17-20

Bouchon A, Hernandez-Munain C, Cella M et al (2001) A DAP12mediated pathway regulates expression of $\mathrm{CC}$ chemokine receptor 7 and maturation of human dendritic cells. J Exp Med 194:1111-1122

Boutajangout A, Wisniewski T (2013) The innate immune system in Alzheimer's disease. Int J Cell Biol 2013:576383

Cagnin A, Brooks DJ, Kennedy AM et al (2001) In-vivo measurement of activated microglia in dementia. Lancet 358:461-467

Carver JA, Rekas A, Thorn DC et al (2003) Small heat-shock proteins and clusterin: intra- and extracellular molecular chaperones with a common mechanism of action and function? IUBMB Life 55:661-668

Choi-Miura NH, Takahashi Y, Nakano Y et al (1992) Identification of the disulfide bonds in human plasma protein SP-40, 40 (apolipoprotein-J). J Biochem 112:557-561

Clark RI, Tan SW, Péan CB et al (2013) MEF2 is an in vivo immunemetabolic switch. Cell 155:435-447

Colonna M (2003) TREMs in the immune system and beyond. Nat Rev Immunol 3:445-453

Conductier G, Blondeau N, Guyon A et al (2010) The role of monocyte chemoattractant protein MCP1/CCL2 in neuroinflammatory diseases. J Neuroimmunol 224:93-100

Cox D, Dale BM, Kashiwada M et al (2001) A regulatory role for Src homology 2 domain-containing inositol 5'-phosphatase (SHIP) in phagocytosis mediated by $\mathrm{Fc}$ gamma receptors and complement receptor 3 (alpha(M)beta(2); CD11b/CD18). J Exp Med 193:61-71

Craft JM, Watterson DM, Van Eldik LJ (2006) Human amyloid betainduced neuroinflammation is an early event in neurodegeneration. Glia 53:484-490

Crehan H, Hardy J, Pocock J (2013) Blockage of CR1 prevents activation of rodent microglia. Neurobiol Dis 54:139-149

Cruchaga C, Haller G, Chakraverty S et al (2012) Rare variants in APP, PSEN1 and PSEN2 increase risk for AD in late-onset Alzheimer's disease families. PLoS One 7:e31039

D'Ambrosio AL, Pinsky DJ, Connolly ES (2001) The role of the complement cascade in ischemia/reperfusion injury: implications for neuroprotection. Mol Med 7:367-382

Davis S, Laroche S (2003) What can rodent models tell us about cognitive decline in Alzheimer's disease? Mol Neurobiol 27:249-276

de Cordoba SR, Rubinstein P (1986) Quantitative variations of the $\mathrm{C} 3 \mathrm{~b} / \mathrm{C} 4 \mathrm{~b}$ receptor (CR1) in human erythrocytes are controlled by genes within the regulator of complement activation (RCA) gene cluster. J Exp Med 164:1274-1283

de Rivero Vaccari JP, Lotocki G et al (2008) A molecular platform in neurons regulates inflammation after spinal cord injury. J Neurosci 28:3404-3414

de Silva HV, Harmony JA, Stuart WD et al (1990) Apolipoprotein J: structure and tissue distribution. Biochemistry 29:5380-5389 
DeMattos RB, O'dell MA, Parsadanian M et al (2002) Clusterin promotes amyloid plaque formation and is critical for neuritic toxicity in a mouse model of Alzheimer's disease. Proc Natl Acad Sci USA 99:10843-10848

Downs-Kelly E, Schade AE, Hansel DE (2007) The role of HLA-G in gastrointestinal inflammatory disease and malignancy. Semin Cancer Biol 17:451-458

Du Yan S, Zhu H, Fu J et al (1997) Amyloid-beta peptide-receptor for advanced glycation endproduct interaction elicits neuronal expression of macrophage-colony stimulating factor: a proinflammatory pathway in Alzheimer disease. Proc Natl Acad Sci USA 94:5296-5301

Duan RS, Yang X, Chen ZG et al (2008) Decreased fractalkine and increased IP-10 expression in aged brain of APP(swe) transgenic mice. Neurochem Res 33:1085-1089

Fan R, DeFilippis K, Van Nostrand WE (2007) Induction of complement proteins in a mouse model for cerebral microvascular A beta deposition. J Neuroinflamm 4:22

Fann DY, Lee SY, Manzanero S et al (2013) Intravenous immunoglobulin suppresses NLRP1 and NLRP3 inflammasome-mediated neuronal death in ischemic stroke. Cell Death Dis 4:e790

Fillit H, Ding WH, Buee L et al (1991) Elevated circulating tumor necrosis factor levels in Alzheimer's disease. Neurosci Lett 129:318-320

Fonseca MI, Kawas CH, Troncoso JC et al (2004) Neuronal localization of $\mathrm{C} 1 \mathrm{q}$ in preclinical Alzheimer's disease. Neurobiol Dis 15:40-46

Forneris F, Wu J, Gros P (2012) The modular serine proteases of the complement cascade. Curr Opin Struct Biol 22:333-341

Frank S, Burbach GJ, Bonin M et al (2008) TREM2 is upregulated in amyloid plaque-associated microglia in aged APP23 transgenic mice. Glia 56:1438-1447

Games D, Adams D, Alessandrini R et al (1995) Alzheimer-type neuropathology in transgenic mice overexpressing V717F betaamyloid precursor protein. Nature 373:523-527

Gasque P (2004) Complement: a unique innate immune sensor for danger signals. Mol Immunol 41:1089-1098

Gasque P, Fontaine M, Morgan BP (1995) Complement expression in human brain. Biosynthesis of terminal pathway components and regulators in human glial cells and cell lines. J Immunol 154:4726-4733

Geier SJ, Algate PA, Carlberg K et al (1997) The human SHIP gene is differentially expressed in cell lineages of the bone marrow and blood. Blood 89:1876-1885

Gemma C, Bickford PC (2007) Interleukin-1beta and caspase-1: players in the regulation of age-related cognitive dysfunction. Rev Neurosci 18:137-148

Giacobini E, Gold G (2013) Alzheimer disease therapy-moving from amyloid-beta to tau. Nat Rev Neurol 9:677-686

Giannakopoulos P, Kovari E, French LE et al (1998) Possible neuroprotective role of clusterin in Alzheimer's disease: a quantitative immunocytochemical study. Acta Neuropathol 95:387-394

Giuriato S, Payrastre B, Drayer AL et al (1997) Tyrosine phosphorylation and relocation of SHIP are integrin-mediated in thrombin-stimulated human blood platelets. J Biol Chem 272:26857-26863

Griffin WS, Sheng JG, Royston MC et al (1998) Glial-neuronal interactions in Alzheimer's disease: the potential role of a 'cytokine cycle' in disease progression. Brain Pathol 8:65-72

Guerreiro RJ, Gustafson DR, Hardy J (2012) The genetic architecture of Alzheimer's disease: beyond APP, PSENs and APOE. Neurobiol Aging 33:437-456

Guerreiro R, Wojtas A, Bras J et al (2013) TREM2 variants in Alzheimer's disease. N Engl J Med 368:117-127
Guo JT, Yu J, Grass D et al (2002) Inflammation-dependent cerebral deposition of serum amyloid a protein in a mouse model of amyloidosis. J Neurosci 22:5900-5909

Guo L, LaDu MJ, Van Eldik LJ (2004) A dual role for apolipoprotein e in neuroinflammation: anti- and pro-inflammatory activity. J Mol Neurosci 23:205-212

Halassa MM, Haydon PG (2010) Integrated brain circuits: astrocytic networks modulate neuronal activity and behavior. Annu Rev Physiol 72:335-355

Hamerman JA, Jarjoura JR, Humphrey MB et al (2006) Cutting edge: inhibition of TLR and FCR responses in macrophages by triggering receptor expressed on myeloid cells (TREM)-2 and DAP12. J Immunol 177:2051-2055

Harold D, Abraham R, Hollingworth P et al (2009) Genome-wide association study identifies variants at CLU and PICALM associated with Alzheimer's disease. Nat Genet 41:1088-1093

Hazen AL, Smith MJ, Desponts C et al (2009) SHIP is required for a functional hematopoietic stem cell niche. Blood 113:2924-2933

Hazrati LN, Van Cauwenberghe C, Brooks PL et al (2012) Genetic association of CR1 with Alzheimer's disease: a tentative disease mechanism. Neurobiol Aging 33:2949, e2945-2949, e2912

Hebert LE, Scherr PA, Bienias JL et al (2003) Alzheimer disease in the US population: prevalence estimates using the 2000 census. Arch Neurol 60:1119-1122

Heneka MT, Wiesinger H, Dumitrescu-Ozimek L et al (2001) Neuronal and glial coexpression of argininosuccinate synthetase and inducible nitric oxide synthase in Alzheimer disease. J Neuropathol Exp Neurol 60:906-916

Henneberger C, Papouin T, Oliet SH et al (2010) Long-term potentiation depends on release of D-serine from astrocytes. Nature 463:232-236

Hickman SE, El Khoury J (2014) TREM2 and the neuroimmunology of Alzheimer's disease. Biochem Pharmacol 88:495-498

Hirsch EC, Hunot S (2009) Neuroinflammation in Parkinson's disease: a target for neuroprotection? Lancet Neurol 8:382-397

Hochgrebe TT, Humphreys D, Wilson MR et al (1999) A reexamination of the role of clusterin as a complement regulator. Exp Cell Res 249:13-21

Hollingworth P, Harold D, Sims R et al (2011) Common variants at ABCA7, MS4A6A/MS4A4E, EPHA1, CD33 and CD2AP are associated with Alzheimer's disease. Nat Genet 43:429-435

Holmes C, Boche D, Wilkinson D et al (2008) Long-term effects of Abeta42 immunisation in Alzheimer's disease: follow-up of a randomised, placebo-controlled phase I trial. Lancet 372:216-223

Hsieh CL, Koike M, Spusta SC et al (2009) A role for TREM2 ligands in the phagocytosis of apoptotic neuronal cells by microglia. J Neurochem 109:1144-1156

Huang Y, Mucke L (2012) Alzheimer mechanisms and therapeutic strategies. Cell 148:1204-1222

Huber M, Helgason CD, Damen JE et al (1999) The role of SHIP in growth factor induced signalling. Prog Biophys Mol Biol 71:423-434

Iida K, Mornaghi R, Nussenzweig V (1982) Complement receptor (CR1) deficiency in erythrocytes from patients with systemic lupus erythematosus. J Exp Med 155:1427-1438

Jankowsky JL, Patterson PH (1999) Cytokine and growth factor involvement in long-term potentiation. Mol Cell Neurosci 14:273-286

Jenne DE, Lowin B, Peitsch MC et al (1991) Clusterin (complement lysis inhibitor) forms a high density lipoprotein complex with apolipoprotein A-I in human plasma. J Biol Chem 266:11030-11036

Jiang H, Burdick D, Glabe CG et al (1994) beta-Amyloid activates complement by binding to a specific region of the collagen-like domain of the C1q A chain. J Immunol 152:5050-5059 
Jiang H, Hampel H, Prvulovic D et al (2011) Elevated CSF levels of TACE activity and soluble TNF receptors in subjects with mild cognitive impairment and patients with Alzheimer's disease. Mol Neurodegener 6:69

Jiang T, Yu JT, Zhu XC et al (2013) TREM2 in Alzheimer's disease. Mol Neurobiol 48:180-185

Jonsson T, Stefansson H, Steinberg S et al (2013) Variant of TREM2 associated with the risk of Alzheimer's disease. N Engl J Med 368:107-116

Kalesnikoff J, Lam V, Krystal G (2002) SHIP represses mast cell activation and reveals that $\operatorname{IgE}$ alone triggers signaling pathways which enhance normal mast cell survival. Mol Immunol 38:1201-1206

Katsel P, Tan W, Haroutunian V (2009) Gain in brain immunity in the oldest-old differentiates cognitively normal from demented individuals. PLoS One 4:e7642

Kerr WG (2011) Inhibitor and activator: dual functions for SHIP in immunity and cancer. Ann NY Acad Sci 1217:1-17

Khiem D, Cyster JG, Schwarz JJ et al (2008) A p38 MAPK-MEF2C pathway regulates B-cell proliferation. Proc Natl Acad Sci USA 105:17067-17072

Kim CH, Hangoc G, Cooper S et al (1999) Altered responsiveness to chemokines due to targeted disruption of SHIP. J Clin Invest 104:1751-1759

Kim JH, Kim JH, Jun HO et al (2010) Protective effect of clusterin from oxidative stress-induced apoptosis in human retinal pigment epithelial cells. Invest Ophthalmol Vis Sci 51:561-566

Klickstein LB, Bartow TJ, Miletic V et al (1988) Identification of distinct $\mathrm{C} 3 \mathrm{~b}$ and $\mathrm{C} 4 \mathrm{~b}$ recognition sites in the human $\mathrm{C} 3 \mathrm{~b} / \mathrm{C} 4 \mathrm{~b}$ receptor (CR1, CD35) by deletion mutagenesis. J Exp Med 168:1699-1717

Klickstein LB, Barbashov SF, Liu T et al (1997) Complement receptor type $1(\mathrm{CR} 1, \mathrm{CD} 35)$ is a receptor for $\mathrm{C} 1 \mathrm{q}$. Immunity $7: 345-355$

Korotzer AR, Watt J, Cribbs D et al (1995) Cultured rat microglia express $\mathrm{C} 1 \mathrm{q}$ and receptor for $\mathrm{C} 1 \mathrm{q}$ : implications for amyloid effects on microglia. Exp Neurol 134:214-221

Lambert JC, Heath S, Even G et al (2009) Genome-wide association study identifies variants at CLU and CR1 associated with Alzheimer's disease. Nat Genet 41:1094-1099

Lambert JC, Ibrahim-Verbaas CA, Harold D et al (2013) Metaanalysis of 74,046 individuals identifies 11 new susceptibility loci for Alzheimer's disease. Nat Genet 45:1452-1458

Lee SC, Zhao ML, Hirano A et al (1999) Inducible nitric oxide synthase immunoreactivity in the Alzheimer disease hippocampus: association with Hirano bodies, neurofibrillary tangles, and senile plaques. J Neuropathol Exp Neurol 58:1163-1169

Leifer D, Golden J, Kowall NW (1994) Myocyte-specific enhancer binding factor $2 \mathrm{C}$ expression in human brain development. Neuroscience 63:1067-1079

Liu L, Chan C (2014) The role of inflammasome in Alzheimer's disease. Ageing Res Rev 15:6-15

Liu D, Niu ZX (2009) The structure, genetic polymorphisms, expression and biological functions of complement receptor type 1 (CR1/ CD35). Immunopharmacol Immunotoxicol 31:524-535

Liu L, Martin R, Chan C (2013) Palmitate-activated astrocytes via serine palmitoyltransferase increase BACE1 in primary neurons by sphingomyelinases. Neurobiol Aging 34:540-550

Lyons GE, Micales BK, Schwarz J et al (1995) Expression of mef2 genes in the mouse central nervous system suggests a role in neuronal maturation. J Neurosci 15:5727-5738

Mandrekar-Colucci S, Landreth GE (2010) Microglia and inflammation in Alzheimer's disease. CNS Neurol Disord Drug Targets 9:156-167

Maresco DL, Osborne JM, Cooney D et al (1999) The SH2containing $5^{\prime}$-inositol phosphatase (SHIP) is tyrosine phosphorylated after Fc gamma receptor clustering in monocytes. J Immunol 162:6458-6465

Matsuoka Y, Picciano M, Malester B et al (2001) Inflammatory responses to amyloidosis in a transgenic mouse model of Alzheimer's disease. Am J Pathol 158:1345-1354

May PC, Lampert-Etchells M, Johnson SA et al (1990) Dynamics of gene expression for a hippocampal glycoprotein elevated in Alzheimer's disease and in response to experimental lesions in rat. Neuron 5:831-839

McGeer PL, McGeer EG (2002) The possible role of complement activation in Alzheimer disease. Trends Mol Med 8:519-523

McGeer PL, Itagaki S, Boyes BE et al (1988) Reactive microglia are positive for HLA-DR in the substantia nigra of Parkinson's and Alzheimer's disease brains. Neurology 38:1285-1291

Medway C, Morgan K (2014) Review: the genetics of Alzheimer's disease; putting flesh on the bones. Neuropathol Appl Neurobiol 40:97-105

Meraz-Rios MA, Toral-Rios D, Franco-Bocanegra D et al (2013) Inflammatory process in Alzheimer's disease. Front Integr Neurosci 7:59

Morgan BP, Gasque P (1996) Expression of complement in the brain: role in health and disease. Immunol Today 17:461-466

Mott RT, Ait-Ghezala G, Town T et al (2004) Neuronal expression of CD22: novel mechanism for inhibiting microglial proinflammatory cytokine production. Glia 46:369-379

Mrak RE, Griffin WS (2005) Potential inflammatory biomarkers in Alzheimer's disease. J Alzheimers Dis 8:369-375

Mrak RE, Sheng JG, Griffin WS (1995) Glial cytokines in Alzheimer's disease: review and pathogenic implications. Hum Pathol 26:816-823

Mulder SD, Nielsen HM, Blankenstein MA et al (2014) Apolipoproteins $\mathrm{E}$ and $\mathrm{J}$ interfere with amyloid-beta uptake by primary human astrocytes and microglia in vitro. Glia 62:493-503

Mullane K, Williams M (2013) Alzheimer's therapeutics: continued clinical failures question the validity of the amyloid hypothesisbut what lies beyond? Biochem Pharmacol 85:289-305

Naj AC, Jun G, Beecham GW et al (2011) Common variants at MS4A4/MS4A6E, CD2AP, CD33 and EPHA1 are associated with late-onset Alzheimer's disease. Nat Genet 43:436-441

Narayan P, Orte A, Clarke RW et al (2012) The extracellular chaperone clusterin sequesters oligomeric forms of the amyloidbeta(1-40) peptide. Nat Struct Mol Biol 19:79-83

Nataf S, Stahel PF, Davoust N et al (1999) Complement anaphylatoxin receptors on neurons: new tricks for old receptors? Trends Neurosci 22:397-402

Natarajan C, Bright JJ (2002) Peroxisome proliferator-activated receptor-gamma agonists inhibit experimental allergic encephalomyelitis by blocking IL- 12 production, IL-12 signaling and Th1 differentiation. Genes Immun 3:59-70

Naya FJ, Olson E (1999) MEF2: a transcriptional target for signaling pathways controlling skeletal muscle growth and differentiation. Curr Opin Cell Biol 11:683-688

Neumann H, Takahashi K (2007) Essential role of the microglial triggering receptor expressed on myeloid cells-2 (TREM2) for central nervous tissue immune homeostasis. J Neuroimmunol 184:92-99

Orr CF, Rowe DB, Mizuno Y et al (2005) A possible role for humoral immunity in the pathogenesis of Parkinson's disease. Brain 128(Pt 11):2665-2674

Otero K, Shinohara M, Zhao H et al (2012) TREM2 and beta-catenin regulate bone homeostasis by controlling the rate of osteoclastogenesis. J Immunol 188:2612-2621

Paloneva J, Manninen T, Christman G et al (2002) Mutations in two genes encoding different subunits of a receptor signaling complex result in an identical disease phenotype. Am J Hum Genet 71:656-662 
Pavlov VA, Tracey KJ (2005) The cholinergic anti-inflammatory pathway. Brain Behav Immun 19:493-499

Pizza V, Agresta A, D'Acunto CW et al (2011) Neuroinflamm-aging and neurodegenerative diseases: an overview. CNS Neurol Disord Drug Targets 10:621-634

Potthoff MJ, Olson EN (2007) MEF2: a central regulator of diverse developmental programs. Development 134:4131-4140

Ransohoff RM (2007) The MHP36 line of murine neural stem cells expresses functional CXCR1 chemokine receptors that initiate chemotaxis in vitro. J Neuroimmunol 186:199 (author reply 200)

Ricklin D, Hajishengallis G, Yang K et al (2010) Complement: a key system for immune surveillance and homeostasis. Nat Immunol 11:785-797

Rogers J, Cooper NR, Webster S et al (1992) Complement activation by beta-amyloid in Alzheimer disease. Proc Natl Acad Sci USA 89:10016-10020

Ruan L, Kong Y, Wang JM et al (2010) Chemoattractants and receptors in Alzheimer's disease. Front Biosci 2:504-514

Sahu A, Lambris JD (2001) Structure and biology of complement protein $\mathrm{C} 3$, a connecting link between innate and acquired immunity. Immunol Rev 180:35-48

Sastre M, Dewachter I, Landreth GE et al (2003) Nonsteroidal antiinflammatory drugs and peroxisome proliferator-activated receptor-gamma agonists modulate immunostimulated processing of amyloid precursor protein through regulation of beta-secretase. J Neurosci 23:9796-9804

Savarin-Vuaillat C, Ransohoff RM (2007) Chemokines and chemokine receptors in neurological disease: raise, retain, or reduce? Neurotherapeutics 4:590-601

Scaltriti M, Bettuzzi S, Sharrard RM et al (2004) Clusterin overexpression in both malignant and nonmalignant prostate epithelial cells induces cell cycle arrest and apoptosis. $\mathrm{Br} \mathrm{J}$ Cancer 91:1842-1850

Seshadri S, Fitzpatrick AL, Ikram MA et al (2010) Genome-wide analysis of genetic loci associated with Alzheimer disease. JAMA 303:1832-1840

Sessa G, Podini P, Mariani M et al (2004) Distribution and signaling of TREM2/DAP12, the receptor system mutated in human polycystic lipomembraneous osteodysplasia with sclerosing leukoencephalopathy dementia. Eur J Neurosci 20:2617-2628

Shen Y, Meri S (2003) Yin and Yang: complement activation and regulation in Alzheimer's disease. Prog Neurobiol 70:463-472

Shen Y, Lue L, Yang L et al (2001) Complement activation by neurofibrillary tangles in Alzheimer's disease. Neurosci Lett 305:165-168

Sherva R, Farrer LA (2011) Power and pitfalls of the genome-wide association study approach to identify genes for Alzheimer's disease. Curr Psychiatry Rep 13:138-146

Sihlbom C, Davidsson P, Sjogren M et al (2008) Structural and quantitative comparison of cerebrospinal fluid glycoproteins in Alzheimer's disease patients and healthy individuals. Neurochem Res 33:1332-1340

Singhrao SK, Neal JW, Rushmere NK et al (1999) Differential expression of individual complement regulators in the brain and choroid plexus. Lab Invest 79:1247-1259

Sly LM, Krzesicki RF, Brashler JR et al (2001) Endogenous brain cytokine mRNA and inflammatory responses to lipopolysaccharide are elevated in the $\mathrm{Tg} 2576$ transgenic mouse model of Alzheimer's disease. Brain Res Bull 56:581-588

Sly LM, Rauh MJ, Kalesnikoff J et al (2003) SHIP, SHIP2, and PTEN activities are regulated in vivo by modulation of their protein levels: SHIP is up-regulated in macrophages and mast cells by lipopolysaccharide. Exp Hematol 31:1170-1181

Sly LM, Ho V, Antignano F et al (2007) The role of SHIP in macrophages. Front Biosci 12:2836-2848
Sofroniew MV, Vinters HV (2010) Astrocytes: biology and pathology. Acta Neuropathol 119:7-35

Strittmatter WJ, Saunders AM, Schmechel D et al (1993) Apolipoprotein E: high-avidity binding to beta-amyloid and increased frequency of type 4 allele in late-onset familial Alzheimer disease. Proc Natl Acad Sci USA 90:1977-1981

Sudduth TL, Schmitt FA, Nelson PT et al (2013) Neuroinflammatory phenotype in early Alzheimer's disease. Neurobiol Aging 34:1051-1059

Swanson BJ, Jack HM, Lyons GE (1998) Characterization of myocyte enhancer factor 2 (MEF2) expression in B and T cells: MEF2C is a B cell-restricted transcription factor in lymphocytes. Mol Immunol 35:445-458

Takahashi K, Rochford CD, Neumann H (2005) Clearance of apoptotic neurons without inflammation by microglial triggering receptor expressed on myeloid cells-2. J Exp Med 201:647-657

Tanzi RE (2012) The genetics of Alzheimer disease. Cold Spring Harbor Perspect Med 2 pii: a006296

Tarkowski E, Issa R, Sjogren M et al (2002) Increased intrathecal levels of the angiogenic factors VEGF and TGF-beta in Alzheimer's disease and vascular dementia. Neurobiol Aging 23:237-243

Tenner AJ (1999) Membrane receptors for soluble defense collagens. Curr Opin Immunol 11:34-41

Thambisetty M, Simmons A, Velayudhan L et al (2010) Association of plasma clusterin concentration with severity, pathology, and progression in Alzheimer disease. Arch Gen Psychiatry 67:739-748

Thambisetty M, An Y, Nalls M et al (2013) Effect of complement CR1 on brain amyloid burden during aging and its modification by APOE genotype. Biol Psychiatry 73:422-428

Torres AR, Westover JB, Rosenspire AJ (2012) HLA immune function genes in autism. Autism Res Treat 2012:959073

Tosto G, Reitz C (2013) Genome-wide association studies in Alzheimer's disease: a review. Curr Neurol Neurosci Rep 13:381

Town T, Nikolic V, Tan J (2005) The microglial "activation" continuum: from innate to adaptive responses. J Neuroinflammation 2:24

Trotta R, Parihar R, Yu J et al (2005) Differential expression of SHIP1 in CD56bright and CD56dim NK cells provides a molecular basis for distinct functional responses to monokine costimulation. Blood 105:3011-3018

Tuppo EE, Arias HR (2005) The role of inflammation in Alzheimer's disease. Int J Biochem Cell Biol 37:289-305

Turnbull IR, Gilfillan S, Cella M et al (2006) Cutting edge: TREM-2 attenuates macrophage activation. J Immunol 177:3520-3524

Urbich C, Fritzenwanger M, Zeiher AM et al (2000) Laminar shear stress upregulates the complement-inhibitory protein clusterin : a novel potent defense mechanism against complement-induced endothelial cell activation. Circulation 101:352-355

Varnum MM, Ikezu T (2012) The classification of microglial activation phenotypes on neurodegeneration and regeneration in Alzheimer's disease brain. Arch Immunol Ther Exp 60:251-266

Vodovotz Y, Lucia MS, Flanders KC et al (1996) Inducible nitric oxide synthase in tangle-bearing neurons of patients with Alzheimer's disease. J Exp Med 184:1425-1433

Walker DG, Dalsing-Hernandez JE, Campbell NA et al (2009) Decreased expression of CD200 and CD200 receptor in Alzheimer's disease: a potential mechanism leading to chronic inflammation. Exp Neurol 215:5-19

White JA, Manelli AM, Holmberg KH et al (2005) Differential effects of oligomeric and fibrillar amyloid-beta 1-42 on astrocyte-mediated inflammation. Neurobiol Dis 18:459-465

Wilker PR, Kohyama M, Sandau MM et al (2008) Transcription factor Mef2c is required for B cell proliferation and survival after antigen receptor stimulation. Nat Immunol 9:603-612 
Wyatt A, Yerbury J, Poon S et al (2009) Chapter 6: the chaperone action of Clusterin and its putative role in quality control of extracellular protein folding. Adv Cancer Res 104:89-114

Wyss-Coray $\mathrm{T}$ (2006) Inflammation in Alzheimer disease: driving force, bystander or beneficial response? Nat Med 12:1005-1015

Wyss-Coray T, Mucke L (2002) Inflammation in neurodegenerative disease-a double-edged sword. Neuron 35:419-432

Wyss-Coray T, Rogers J (2012) Inflammation in Alzheimer disease-a brief review of the basic science and clinical literature. Cold Spring Harbor Perspect Med 2:a006346

Xie Z, Harris-White ME, Wals PA et al (2005) Apolipoprotein J (clusterin) activates rodent microglia in vivo and in vitro. J Neurochem 93:1038-1046

Yang LB, Li R, Meri S et al (2000) Deficiency of complement defense protein CD59 may contribute to neurodegeneration in Alzheimer's disease. J Neurosci 20:7505-7509
Yerbury JJ, Poon S, Meehan S et al (2007) The extracellular chaperone clusterin influences amyloid formation and toxicity by interacting with prefibrillar structures. FASEB J 21:2312-2322

Yoshiyama Y, Lee VM, Trojanowski JQ (2013) Therapeutic strategies for tau mediated neurodegeneration. J Neurol Neurosurg Psychiatry 84:784-795

Yu JT, Tan L (2012) The role of clusterin in Alzheimer's disease: pathways, pathogenesis, and therapy. Mol Neurobiol 45:314-326

Yu YT, Breitbart RE, Smoot LB et al (1992) Human myocyte-specific enhancer factor 2 comprises a group of tissue-restricted MADS box transcription factors. Genes Dev 6:1783-1798

Zou J, Crews FT (2012) Inflammasome-IL-1beta signaling mediates ethanol inhibition of hippocampal neurogenesis. Front Neurosci $6: 77$ 